\title{
THE [NOT SO] HIDDEN CURRICULUM OF THE LEGALIST STATE IN THE BOOK OF LORD SHANG AND THE HAN-FEI-ZI
}

\author{
BRANDON KING
}

\begin{abstract}
This paper draws some parallels between the experience of a subject in a socalled "Legalist" state with that of a contemporary student in Western schooling today. I explore how governance in the Book of Lord Shang and the Han-Fei-Zi can be interpreted as pedagogy. Defining pedagogy in a relatively broad sense, I investigate the rationalizations for the existence of the state, the application of state mechanisms, and even the concentration of the ruler's power and how they teach subjects habits, attitudes, and sensibilities in a similar fashion to what Philip Jackson called the "hidden curriculum". Through his framework of "crowds, praise, and power" this paper will explore how governance teaches and what those subjected to it learn. This study also attempts to provide some insight into the usefulness of approaching "Legalist" texts with a positive sociological lens.
\end{abstract}

Keywords: Book of Lord Shang, education, governance, Han-Fei-Zi, hidden curriculum, law, legalism, pedagogy, Philip Jackson

This study argues that the governance described in the Book of Lord Shang and the Han-Fei-Zi can be understood as pedagogy. ${ }^{1}$ For obvious and understandable reasons, discussions of pedagogy have been most associated with the Confucian tradition. ${ }^{2}$

KING, Brandon: Postdoctoral Fellow, University of Pennsylvania, USA. Email: brandon.r.king24@gmail.com

\footnotetext{
${ }^{1}$ For the sake of brevity, I bring the readers' attention to three important notes. First, from this point forward, I will refer to the Book of Lord Shang with the acronym "BLS" and the Han-Fei-Zi with the acronym "HFZ" in italicized formats. Second, I will not engage in a discussion over the ways the term "Legalist" has been problematized. A discussion of this can be found in Goldin (2011). Generally, I follow the argument put forth for the term "Legalist" in King (2015). Third, I focus this paper's analysis on the $B L S$ and the $H F Z$. This does not imply that this paper's framework cannot be applied to the "Shenzi fragments", the "Shen Buhai fragments", and the Guan-Zi. I only focus on the BLS and the $H F Z$ because they provide the most elaborate discussions on the specific aspects of the Legalist state this study examines. To be clear, I would argue that the framework discussed in this paper can be used to understand the foundation of ideal states discussed in other so-called Legalist texts, such as the "Shenzi fragments", the "Shen Buhai fragments", and the Guan-Zi.

${ }^{2}$ Recent social scientific and cultural studies research has explored how Confucian ideas about education shape educational practices in China today, such as Huang and Asghar (2018).
} 
Additionally, the $B L S$ and the $H F Z$ contain passages that are seemingly antieducation. For instance, the $B L S$ chapter “Agriculture and Warfare" (Non-Zhan 農展) quite famously attacks the pedagogy of the Confucian moral cultivation process saying that if a state possessed the Book of Odes, Book of History, rites, music, goodness, cultivation, benevolence, and other markers of pre- $B L S$ Confucian learning outcomes, the state will necessarily become dismembered, poor, or both. (Gao 2011, 49) ${ }^{3}$ However, the "pedagogy" to which I refer is broader in nature. It does not transmit an overt curriculum for the sake of individual cultivation. Rather, this pedagogy puts forth guidance for a collective culture and condition through a specified state practice. This broad sense of pedagogy shares similarities with what scholars call "public pedagogy" today, which generally describes the "...spaces, sites, and languages of education and learning that exist outside of the walls of the institution of schools". (Sandlin, Schultz, and Burdick 2010, 1)

The emphasis of this study is on philosophical interpretation rather than historical description. For understandable reasons, like their relentless advocacy for an intense concentration of power in the hands of the ruler, Legalist texts have been examined with perspectives that center themselves around the ruler, his interests, his relationship with his ministers, and the advantages and disadvantages of utilizing one or more of his political tools. Nevertheless, my examination will be guided by my own inquiry's focus, which will hopefully complement the differing perspectives from previous research. For instance, earlier studies of Legalist texts have identified their assignment of greater importance to punishments rather than rewards for legal reinforcement. Yet, this study's interest lies more on the rewards aspect of the law since it is the state's most powerful tool for encouraging positive action.

Rather than attempting to understand the envisioned Legalist state culture through an analysis of the ruler's interest and his objectives according to what is explicitly stated in the texts, I begin with how the common subject experiences state governance while remaining grounded in the $H F Z$ 's explicitly stated assumptions about human nature and the $B L S$ 's implied assumptions about human behavior. The hope is that consistent attention paid to the perspective of the subject will bring to light some effects of Legalist governance that have remain undiscussed. Investigating what is political about culture, this study focuses on how the "pedagogical" becomes a "defining feature of cultural politics" (Giroux 2000, 342) in the Legalist state. Consider C. Wright Mills's discussion of what he called the "cultural apparatus". (Mills 2008, 204) As Mills explained it, a person is not the sole author of her own consciousness. Between people and their lived experience lies images, meanings, and

\footnotetext{
${ }^{3}$ Yuan (2017) points out that the $H F Z$ argues against Confucian moral cultivation by characterizing it as a process that generates social expectations that deviate strongly from human nature and cause a resentment that the ideal Legalist state seeks to eliminate. (Yuan 2017, 24). Xu (2012) explains that passages like the aforementioned from "Agriculture and Warfare" [3] must be understood as an illustration of the $B L S$ 's rejection of the idealistic moral education in favor of the more practical view that virtue has its origins in state punishments. (Xu 2012, 198) In fact, Xu asserts that the hope for a moral society is obvious in the $B L S$. It is simply that the text only conceptualizes morality as a product of a process of governance rather than an integral component of social management. (Xu 2012, 216)
} 
ways of living or organizing on which individuals depend to establish what they understand as "solid fact, sound interpretation", and "suitable presentations". (Mills 2008, 204) Even more directly, Mills said:

The cultural apparatus not only guides experience; often as well it expropriates the very chance to have experience that can rightly be called 'our own.' For our standards of credibility, our definitions of reality, our modes of sensibility - as well as our immediate opinions and images - are determined much less by any pristine experience than by our exposure to the output of the cultural apparatus. (Mills 2008, 204)

For our specific purposes, pedagogy can be understood to refer to the techniques and methods that reinforce what I am calling "state values"4, or subject pursuits of personal gain that are most positively reinforced by the ruler, and their promoted cultural and sociopolitical practice.

In order to facilitate a consistent perspective that focuses on subject responses to culture, I use contemporary thought on U.S. education to guide my analysis of ancient texts. This of course would not be the first exploration of the Legalist state's educational aspect with a sociological twist. ${ }^{5}$ However, this paper seeks to reveal some shared cognitive structures within which subjects construct their social reality and navigate networks of relationships in all Legalist texts. This contributes to our ability to answer questions like: What is the textual core of the Legalist tradition? What distinctively shared characteristics do the ideal states in Legalist texts possess? Moreover, a comparison with contemporary thought on U.S. schooling can advance our understanding of the sociology of education that lies at the foundation of the Legalist state's power and legitimacy. If the earlier Marxist or Neo-Marxist critiques of U.S. schooling have a shred of merit, then we can say that both U.S. schooling and the Legalist state demonstrate institutional concern for how to socialize and train people to develop a shared consciousness that conforms to the control of a governing body. This enables us to not only heighten our awareness of Legalist subjects' cognitive structures, but it also makes our knowledge of the mechanisms or objective structures that produce these cognitive structures more comprehensive.

Within this context, I propose that we consider thinking of the ideal state described in the $B L S, H F Z$, and other Legalist texts as having a "hidden curriculum".

\footnotetext{
${ }^{4}$ Schneider suggests that rather than "values", the $H F Z$ ideal state possesses a public "justice" (gong-yi 公義), one of “order giving and order taking" (Schneider 2014, 30), that aligns the ruler's interests with those of his ministers and the rest of his populace. However, following King (2015), this paper will solely focus on the foundation of the distinctly shared characteristics of Legalist texts: their unique conception of law. Thus, this study's conception of values refers to what the Legalist state's law delineates as desirable and undesirable behavior. Even more specifically, the activities that state law most positively reinforces are agriculture and warfare. As a result, this study considers the pursuit of the aforementioned two state-promoted channels in accordance with state values.

${ }^{5}$ Handleman pointed out that the notion of law in the $B L S$ has a taxonomic character that actively organized knowledge and posited "relationships among categories that are manipulated in order to attain" the goals of the state bureaucracy. (Handelman 1995, 277)
} 
(Jackson 1983, 56) First introduced by Philip Jackson, it can be roughly defined as that which is learned outside of a formal and overt curriculum. Focusing his attention on the characteristics of contemporary schooling in the United States, Jackson summarizes a child's experience with three "facts of life": "crowds, praise, and power". (Jackson 1983, 35) The comparison of the U.S. student's experience of the hidden curriculum and the Legalist subject's experience of state governance provides a framework that can reveal new dimensions of the envisioned Legalist state's culture and introduce new perspectives on already explored aspects. It is mainly in this sense that the ideal state in the $B L S, H F Z$, and other Legalist texts can be said to have a public pedagogy of their own.

\section{CROWDS}

Differing from an educational environment in which a teacher could instruct "one student at a time", Jackson argues that teachers must channel social traffic, manage the flow of classroom dialogue, monopolize the allocation of classroom resources, grant special privileges, and even serve as an official time-keeper in response to the "crowded condition of the classroom". (Jackson 1983, 37) In turn, students learn from their experience of these teacher strategies to "delay" and deny their impulses and desires, developing an understanding of the value of deferred gratification, while also learning to be alone in a crowd. (Jackson 1983, 38-41) These lessons essentially teach students that "learning to live in a classroom" means learning to live as one member of a crowd. (Jackson 1983, 35) In the HFZ, “The Five Vermin" ( $W u$-Du 五蛽) $[1]^{6}$ suggests that life as a member of the state teaches the subject to identify as one of many countrymen over which a governing entity presides. (Chen 2000, 4.14.10871088) Most remarkable for our purposes is the chapter's attention to population. The amount of people within a form of human organization is identified as a determining factor of the need for governance. During antiquity, there was no need for tilling and weaving because the resources of the natural world were in such abundance in relation to the population of human beings at the time. ${ }^{7}$ This lack of scarcity for resources had two main consequences. The first is that the people did not contend or fight with one another for resources. The second is that the people governed themselves, making a government unnecessary.

\footnotetext{
${ }^{6}$ The passages to which I refer will be from various chapters in both the $B L S$ and the $H F Z$. However, since I refer to chapter forty-nine a few times, I have made an effort to distinguish each passage from "The Five Vermin". Therefore, I follow the following format [chapter name (in pinyin and Chinese)][chapter number][order of appearance in this paper]. This first "The Five Vermin" passage will be labeled “The Five Vermin" ( $W u$ - $D u$ 五蛽) [1], the second “The Five Vermin" [2], the third "The Five Vermin" [3], etc.

${ }^{7}$ Song even adds that this chapter's account of history even illustrates how subjects of the HFZ's ideal state actually choose their ruler through an evaluation of how a sovereign effectively resolves the most pressing social problems. Although this study does not find such an assertion consistent with other chapters in the $H F Z$, the notion that the ideal ruler should, at least in part, serve the people is an idea that Legalist texts do appear to share with other Warring States traditions of thought. (Song 2007, 39)
} 
However, after a population boom exponentially increases the ratio of human beings to natural resources, antiquity's form of human organization, which did not include government, reached a breaking point. Contention amongst the people arose and government was needed to regulate human pursuit of material welfare and distribute resources optimally. Although our passage does admit that the ratio of human beings to natural resources can reach a point where government can struggle to produce order, it is nevertheless clear that "crowds" or a large population is a fundamental aspect of life as a state subject. In other words, all subjects must learn how to live and be treated as a member of a large collective of countrymen who, in relation to a governing entity, have a similar status. Further, the quality of one's membership in the state collective is largely expressed through how his pursuit of material welfare cooperates with governance.

The $B L S$ rationalizes the formation of government in a remarkably similar fashion. "Opening the Blocked" (Kai-Sai 開賽) famously provides a description of how the state was formed. (Gao 2011, 84) In this opening passage of the chapter, the $B L S$ clearly demonstrates its awareness of how population increase and existing social problems mandated change for the structure of human relations after antiquity. Most importantly, it notes how human organization is conceptualized as a response to a pressing social problem related to the scarcity of resources: competition. During antiquity, people did not need to understand themselves as members of a larger collective beyond their close relatives initially. Over time though, contention in social relations arose because the population was acutely atomized. Individuals and their small familial units saw little reason to concern themselves with the welfare of those outside of their group.

Yet, soon this lack of concern for non-relatives became the gasoline on the fire that was the competition for resources. The desperate need to alleviate social conflicts and the general insecurity from the seizing of each other's property brought about the elevation of the worthies (xian 賢). These individuals put forth useful ideas for conflict resolution and prevention, such as impartiality, propriety, benevolence, and selflessness. This form of human organization also failed to sufficiently teach subjects to identify as members of a unified collective. Within this structure of social relations, the benevolent and worthy still devoted themselves to the pursuit of profit and competition in ways that produced chaos once more. It was only when the sage establishes regulations, officials, and the position of the ruler that lasting unity within human social relations was attained.

In short, the $B L S$ indicates that the institutionalized state uniquely trained people to assume a particular identity: the governed subject. ${ }^{8}$ More specifically, a subject is one member of a collective larger than his relatives or network of acquaintances to which he owes certain obligations. Hence, the Legalist state cannot be adequately characterized by even the most thorough discussion of authority. We must also

\footnotetext{
${ }^{8}$ This rationale for the state challenges Zhao's assertion that the "Legalists' only justification for draconian penal laws was their effectiveness in generating manpower and resources for war". (Zhao 2015, 185-186)
} 
understand it as a collective whose membership requires responsibilities that transcend all others, even those to interpersonal relationships with family and friends. This is perhaps most pronounced on the issue of scarcity.

Jackson asserts that "one of the inevitable outcomes of traffic management is the experiencing of delay". (Jackson 1983, 38) Relative to antiquity, the creation of the state necessarily delays an individual's obtainment of material resources and profit through mandating certain conditions within which it takes place. The state regulates all subjects' pursuit of personal gain so as to avoid the inevitable chaos that would otherwise ensue. As a result, to be a "subject" fundamentally means being a person whose desire is subject to the control of the state. In some cases, the state requires a subject to completely deny or give up certain desires (i.e. murdering out of rage or revenge for a family member or close acquaintance). In other cases, the state will demand that a countryman delay action for the sake of satisfying his impulses and desires. This is illustrated by the Legalist state's requirement that subjects engage in what they dislike (agriculture and warfare) as a condition for obtaining what they like (profit and fame).

In any case, the formation of the state depicted in our "The Five Vermin" [1] and "Opening the Blocked" passages results in members of this new collective submitting themselves to a moderation of their desire that is conducive to all countrymen avoiding the conflict and general insecurity experienced during times of social chaos. ${ }^{9}$ Indeed, subjects exercise a self-control, that is of course initiated by the state, for their own personal gain. However, when a subject behaviorally acknowledges the fact that he is "one of many" in a collective, it clarifies the inseparability between his personal gain and the welfare of his fellow countrymen. Being "one of many" in a collective requires that an individual subject behaviorally prioritize obligations to his new collective.

On the other hand, commitment to country is primarily one to state practice rather than the people with whom a subject interacts on a daily basis. In this aspect, the subject is also required to ignore other members of his collective, encountering "conditions of social solitude". (Jackson 1983, 41) When fellow countrymen are engaging in malfeasance or out of step with state practice, the ideal countryman must learn to not only contribute to state objectives as he actively pursues his own personal gain but also to ignore the social distraction from those who do not. This aspect of collective life can contrarily intensify a sense of isolation. Even when witnessing others experience the pleasures that excess desire can provide, subjects must always remind themselves of their duties to contribute to state objectives and remain steadfastly committed to them.

\footnotetext{
${ }^{9}$ In fact, Ding explicitly argues that Legalist texts advocate that the ideal subject should refrain from extravagant living. (Ding 2016, 34) The $B L S$ completely rejects all forms of extravagance (Ding 2016, 36) but limits its discussion of frugality and extravagance to the realm of administering a state (Ding 2016, 36). The $H F Z$ does encourage extravagance to a limited degree. For instance, Ding points to the "On Assumers" chapter and says that the state can still be in good order when the ruler is extravagant so long as he is able to distinguish between the beneficial and detrimental in his minister's words and grasps his authority tightly. (Ding 2016, 36)
} 
So if one were to ultimately distill what the "crowds" aspect of the Legalist state teaches its subjects into an attribute, it would have to be the ability to defer gratification. ${ }^{10}$ Consisting of the delay or denial of personal desire, this deferred gratification requires countrymen to engage in a serious balancing act between giving in to impulse and completely giving up on it. The Legalist state does not demand the lack of desire but rather a degree of patience and self-control to pursue the satisfaction of desire under very specific conditions. This does not fundamentally alter what the HFZ describes as human nature: the inclination to gravitate towards safety and profit and avoid danger and harm. (Chen 2000, 4.14.279) Yet the way (violent struggle) in which human nature manifested itself behaviorally prior to the formation of the state significantly changes to include a deferred gratification characterized more by a subject's inaction than his actions.

\section{PRAISE}

On the aspect of "praise", Jackson says that a student "must learn to adapt to the continued and pervasive spirit of evaluation that will dominate his school years. (Jackson 1983, 43) Generally, the use of praise in order to motivate behavior in others is not uniquely Legalist. In his notes for the Analects 8:19 (Lau 1992, 72), Slingerland mentions how the legendary monarch Yao is being praised for transforming his subjects, naturally and effortlessly changing their behavior. (Slingerland 2003, 84) When Analects 8:19 is read in conjunction with the Analects 4:17 (Lau 1992,32) it is even more revealing. The combination of the two passages illustrates the pedagogical function of morally exemplary figures. Yao acts as a model that inspires cultivators of morality to attain similar levels of moral accomplishment. Those being shown the virtues of Yao's behavior and accomplishments are supposed to be motivated and even more committed to equaling Yao's example.

Olberding points out that children develop sensibilities "about what it is to be a person, and to be a good person, by watching and imitating others" pre-theoretically, or before they actually understand moral precepts. (Olberding 2012, 33) In this sense, the process of emulating an exemplary figure fundamentally possesses a "primitive character", stimulating a person's desire to become what they want to be like. (Olberding 2012,34) She continues to explain that a child, even in this pre-theoretical phase, does not merely emulate actions but comprehensively appropriates attitudes, emotions, and demeanor while appreciating their context-dependence. Also, the distance between the desire to emulate and evaluative judgments is negligible. In other words, in order to decide what a girl wants to be like, she must also make statements about what she does not want to be like. As this child places value on what she wants to be like, it logically follows that what she wants to be like is better than what she does not want to be like. (Olberding 2012, 33-34)

\footnotetext{
${ }^{10}$ Jackson argues that delay and denial teach students patience as a moral attribute rather than an adaptive strategy because it is what a student is asked to be rather than what she must do. (Jackson 1968, 42)
} 
The Mozi even advocates for an institutionalized form of praising and scolding through state laws ( $f a$ 法). However, Heaven (tian 天) is the ultimate authority of state law and source of culture. The behavior that rewards and punishments reinforce in the Mozi is also different. The "Exalting Worthiness" chapters advocate that the state encourage a combination of virtue and capability. The text explains that the sage kings "selected those who were worthy and gave them high positions", "enriching and enobling them", while "they curbed and demoted" "those who were unworthy", "impoverishing and debasing them by making them followers and servants". (Johnston 2010, 63) Lowe adds that the "identification with the superior" aspect of the Mozi's thought is "intimately intertwined" with the idea of exalting worthiness. (Lowe 1992, 85) The "superior" or those in higher positions must be the "ethical better of the subordinates who are to identify with him". (Lowe 1992, 88)

We should also note that the Mozi's rewards and punishments facilitate a fundamentally cooperative state, representing the cultural antithesis to the Legalist ideal vision. As Johnston explains, the lowest three levels of the Mozi's five-tiered hierarchy relied on the reporting of extraordinarily good and bad conduct. (Johnston 2010, xli-xlii) This not only suggests that the contingent quality of rewards and punishments was weak, relative to the ideal Legalist state, but the rewards are supposed to reinforce acts of mutual concern and mutual benefit (jian-xiang-ai jiaoxiang-li 兼相愛交相利) amongst subjects rather than a contribution to state wealth and strength. The precondition for becoming wealthy and privileged in this ideal state requires the direct benefit of other subjects.

However, in stark contrast to the Analects, the HFZ, along with our aforementioned "Opening the Blocked" passage, quite clearly rejects the idea that worthies or morally exemplary figures were sufficient to govern the state or even to teach others who lack such extraordinary personal qualities. ${ }^{11}$ Additionally, the aforementioned "Agriculture and Warfare" passage clearly rejects Confucian ritual. At the same time, the $B L S$ expresses the necessity to ensure that rewards and punishments correspond to the desires of the people in the chapter "Implementing Laws" (Cuo-Fa 錯法). (Gao 2011, 59) The HFZ also elaborates on the use of rewards and punishments as institutionalized forms of praising and scolding in "The Two Handles" (Er-Bing 二柄). (Chen 2000, 2.7.120) The opening passage of the chapter conveys how rewards act as institutionalized forms of praise that are meant to perpetually motivate subjects to pursue their personal gain within state-promoted channels. Punishments act as institutionalized forms of scolding that are meant to continuously discourage subjects from pursuing their personal gain outside of rulerapproved channels or engaging in any other kind of behavior in opposition to state expectations. The state's application of rewards and punishments become a

\footnotetext{
11 “A Critique on Circumstantial Advantage” (Nan-Shi 難勢) advocated the superiority of positional power ( $s h i$ 勢) above a form of statecraft in which the ruler leads by example when it explains that the legendary ruler Yao, known for his extraordinary virtue and governance, as a commoner, was unable to manage three families. (Chen 2000, 17.40.939)
} 
commentary on the degree to which an individual subject fulfills state objectives and expectations.

Since the spirit of evaluation is at the very foundation of the state's architecture of governance, it follows that subjects will be acutely aware of the sources of their evaluation. I argue that it comes from three places. The first source of evaluation is the ruler himself. Only the ruler can create and change the laws or bestow rewards and apply punishments. All officials follow the ruler's command. Hence, if a subject is impoverished with base status in society, he knows the ruler thinks of his worth as lowly.

Secondly, fellow countrymen, or more specifically their relative material circumstances, represent another source of subject evaluation. Consider the assumptions the HFZ makes about human behavior: people gravitate towards profit and avoid harm or loss. If we translate this idea into a social context, it follows that subjects will tend toward the activities and behavior of the wealthy and noble. In other words, the relative deprivation of material welfare and social privilege suffered by a social inferior will motivate him to equal or surpass his social superiors. In order to do so, he will identify with the behaviors, activities, and qualities of performance of social superiors that yield greater personal gain.

In this sense, despite the $B L S$ and $H F Z$ rejecting the possibility that worthies and morally exemplary figures could efficaciously produce political or social order, the ideal state puts all subjects in a similar position to the child from Olberding's example. This is not to say that social superiors lead social inferiors by example. Social superiors are merely the embodiments of the wealth and nobility that awaits social inferiors upon their pursuit of personal gain within state-promoted channels. While social inferiors naturally pursue their own personal gain, they do not naturally do so within state-specified conditions. Therefore, social superiors serve as additional reinforcement for what the state considers desirable behavior, which may require certain attitudes and sensibilities, or actions that enable inferiors to obtain personal gain while fulfilling their state duties.

These state dynamics suggest that, just as the child does in Olberding's example, Legalist subjects can develop characteristics before understanding what it is to be an ideal subject. This is because, in their pre-theoretical phase, they not only emulate the action of pursuing personal gain within ruler-approved channels, but they "comprehensively appropriate" the "context-dependent" attitudes, emotions, and demeanor associated with successful pursuits. Before they understand state values embedded in the law, they develop context-dependent characteristics for the sake of obtaining the wealth and nobility they desire rather than becoming a good person. Also, in accordance with their nature, subjects will of course assign value to wealthy and impoverished conditions. Therefore, what subjects want (wealth and nobility) will be thought of as better than what they do not want (impoverishment and baseness). This, by extension, creates a state culture within which the wealthy and noble are considered better than the impoverished and base.

We should also note that social reinforcement would not simply flow down the social and political ladder. It is also the case that social inferiors serve as 
embodiments of deprivation for their superiors. They warn the relatively wealthy and privileged of the impoverishment and marginalization that awaits if they fail to complete state tasks or develop the habits, ideas, feelings, and qualities of character they mandate. Hence, rewards and punishments transform people who were simply adversaries (or allies) in the forms of human organization that preceded the institutionalized state into personified extensions of legal reinforcement, representing the varying fates that await different performances in state-promoted channels.

The third source of evaluation, a corollary to the second, is the subject himself. The material circumstances of his life and the social reinforcement it receives informs the subject about how he should value himself. Also, if he is supposed to fundamentally view himself as one member of a collective, how does the subject not self-judge harshly when his community considers his membership unproductive and contemptible? How a countryman should value himself is repeatedly made visible and public in his everyday life.

"The Five Vermin" [2] confirms that the way the state manipulates material conditions can stimulate the natural human inclination to avoid such impoverishment and ignobility. The chapter illustrates how the people come to understand that agriculture and war are the only paths to profit and fame. (Chen 2000, 19.49.11111112) The potential for profit (wealth) and fame (nobility) not only causes subjects to overcome their aversion to toil and danger but it also transforms their behavioral response to these stimuli. Perhaps more importantly, ruler-approved channels produce new thought and behavior from the populace. Externally or behaviorally, the people embrace the toil and danger of agriculture and warfare instead of evading them. Internally, they recognize the necessity of overcoming their initial responses to toil and danger for the sake of the personal gain within ruler-approved channels.

Along with the three sources of evaluation, this study argues that there are also two main areas in which subjects are evaluated. First, subjects are evaluated on their contributions to state objectives. We can think of this area as the "rewards aspect" of the law that is based on a culture of merit. Revealing the mechanical quality with which the state responds to its subjects, extraordinary performances in agriculture or warfare are rewarded according to the letter of the law. Generally such behavior is positively reinforced with merit. This is designed to reinforce the direction and quality with which subjects perform their meritorious acts. Upon the accumulation of a certain amount of merit, countrymen are awarded rank, associated with greater wealth and social status. In this sense, merit itself is a record of an individual subject's contributions that are recognized by the state. This is reminiscent of the "semipublic record of progress" and aptitude a child experiences in classroom life. (Jackson 1968, 43)

Pines has illustrated that this rewards aspect of law possesses an undeniable historical significance. "Military distinction", or rewards earned from "the beheading of enemy combatants", served as the "primary means of advancing up the social ladder". (Pines 2017, 72) Rank was "not a hollow honor" but rather one that entitled "owners to manifold social and economic benefits and eventually the right to join officialdom". (Pines 2017, 72) Now of course, the Qin system of rewards did not 
completely ignore the aspect of individual performance that is inseparable from collective success. Extraordinary individual performance on the battlefield was not recognized if the individual's unit suffered deaths. (Pines 2017, 72) In other words, individual performance was recognized as a function of its contribution to group success. This is entirely consistent with this study's depiction of the ideal Legalist state.

The second area of evaluation is legal compliance. We can think of this as the "punishment aspect" of the law. This aspect of state governance is primarily concerned with the degree to which a subject complies with state behavioral expectations. Crimes are evaluated and punished according to the letter of the law. In other words, there is an important distinction to be made between the unproductive subject and the criminal. The criminal fails to conform to state behavioral expectation, stealing, killing, or violating the law in other ways. The unproductive subject, though not ideal, does not necessarily deserve to be punished. He simply doesn't merit reward.

It should be noted however that within our first main area of subject evaluation, contribution to state objectives, the HFZ indicates an awareness of the impact character traits can have on the wealth and strength of the state. When I refer to character traits I point to the attitudes, sensibilities, and personal qualities that are required to successfully perform extraordinarily within ruler-approved channels while also being legally compliant. In the discussion about "crowds", this study has already mentioned how the ability to defer gratification required a certain degree of patience and self-control. In essence, rewards are not just bestowed on those who are the smartest or the most physically strong. They must be bestowed on those that channel these abilities most effectively into ruler-approved pursuits. In other words, what is rewarded is not just demonstrated ability but how subjects perform them.

“Inner Compendium of Explanations, Upper” (Nei-Chu-Shuo-Shang 內儲說上) provides an example of how legal reinforcement can not only shape abilities and sensibilities but also produce a new attitude within the hearts of the populace as well. Referring to both general recognition and reward, "Inner Compendium of Explanations, Upper" tells us how King Gou Jian prepared his populace for war by publically recognizing and celebrating a frog with an aggressive energy and spirit ( $q i$ 氣). (Chen 2000, 9.30.598-599) Even though the King is mainly concerned with the wealth and strength of the state, the frog's look and assumed temperament possessed an aggressive energy and spirit the King felt his people lacked. The act of elevating the frog served as pedagogy, teaching the King's populace about the new energy and spirit that it needed to acquire. The King's men-of-service were particularly affected by the elevation of the frog. Even though they were already considered to be brave (yong 勇), the King's recognition of the frog rather than of them, motivated the menof-service to develop a new characteristic.

Also, the text refers to the King's elevation of the frog as a teaching (jiao 教). If the reader interprets this teaching as merely informing the people of "where their benefit lies and whence danger comes" (Pines 2017, 92), she would fail to 
comprehensively understand the complete educational process at work. Although a subject's knowledge of the activities that will yield personal gain is necessary in the above passage, it is not a sufficient learning outcome. Since the King wanted to attack the state of $\mathrm{Wu}$, he sought to instill an aggression or bellicosity that he believed was required to succeed. So it was not enough for the King to dictate the actions of his people. He needed to see a development in their character before he launched an attack against the state of $\mathrm{Wu}$. This explains why subjects reacted to the recognition of the frog by chopping off their own heads and offering them to the King.

The King's elevation of the frog is analogous to the HFZ's administration of law in the way that recognition was used to motivate the populace. The relative deprivation experienced by the populace, particularly the brave men-of-service, was the main motivating force. When the frog was recognized and established as a model to follow, the condition in which subjects felt relatively less valued caused them to develop a similarly angry or bellicose temperament. Also, aggressiveness, assumed from the frog's appearance, was made a desirable trait. In another other version of this same story, the King's intention behind promoting the angry frog was that he wanted to cause all of his subjects to make light of death. (Chen 2000, 9.30.598) Both stories ultimately depict a King who hoped to inculcate more bravery and bellicosity into countrymen. Therefore, the King's elevation of the frog as a model indicates that he viewed bellicosity as an important characteristic for success on the battlefield.

It is also important to note how punishment is not even included in this story. This not only highlights the punishment-like effect the text assumes relative deprivation to possess, but it also illustrates how rewards/recognition act as a "positive means of encouraging the people's commitment to warfare". (Pines 2017, 94) Yet, rewards/recognition are not simply tools used to facilitate relative deprivation. The King's recognition of the frog itself proclaims the state's high valuation of a task that required the kind of aggression or bellicosity that enhances the state's military might. Representing a standard in itself, this "adoration of the martial spirit" (Pines 2017, 94 ) is meant to pervade society and become ingrained in state culture. If rewards are indeed bestowed for soldier success on the battlefield and bellicosity is considered a necessary characteristic for it to occur, then it follows that bellicosity will be a characteristic that will legitimate a countryman's material welfare and social privilege. This of course then teaches subjects that bellicosity is one category by which they should evaluate themselves and others in society.

Our frog story additionally described the quality with which soldiers fought as lacking compassionate hearts. This further supports the notion that the King's statecraft generated a process in which the people developed a state-specific bellicosity. Unconcerned with the dangers or the welfare of others who are not fellow countrymen in battle, this instillation of bravery is reminiscent of that found in the $B L S$ 's "Eliminating the Strong" (Qu-Qiang 去強). One passage suggests that punishments are what effectively diminish the timidity (qie 怯) toward warfare, which grows out of a cowardly concern for self-preservation at the expense of state development, and instills a disciplined ruthlessness and toughness. However, rewards 
make the instilled ruthlessness and toughness state-specific, refining and perfecting it to benefit the concerns beyond the subject's self. (Gao 2011, 59)

This disciplinary process within the demarcating lines of rewards is very similar to one aspect of the rites in the Analects. The rites are supposed to help the selfcultivator reach an understanding or mastery of virtue, acting as boundaries within which individuals behave. These boundaries are what keep the self-cultivator's sensibilities, attitudes, and virtues properly channeled. Levi essentially tells us that the ideal Confucian ruler governed society through ritual, putting forth an education that achieves a "veritable political indoctrination", "under the cover of turning customs into a police and inspiring the populace" with virtue. (Levi 2011, 684) For Legalists, the law replaces ritual and, in some ways, performs a similar function. Given the negative connotation the term 'zheng' (爭) has in both the HFZ and the $B L S$, the proper channeling of bravery in the "Legalist" context is abroad. We will soon see that the HFZ's "Outer Compendium of Explanations, Lower Right" (WaiChu-Shuo-You-Xia 外儲說右下) even asserts that domestic infighting is worse than people starving to death. (Chen 2000, 14.35.818-819)

I dare say that the law's channeling of aggression and violence abroad in the $B L S$ and the $H F Z$ is similar to the rites channeling of expressions of virtue in the Analects 8:2. (Slingerland 2003, 78) Slingerland notes that this "first half" of the passage "has to do with the ability of ritual to trim and shape native tendencies so that they fit the mean of true virtue". (Slingerland 2003, 78) When virtue is expressed outside the confines of the rites, the self-cultivator can lose sight of the ultimate objectives of practicing the rites: harmonious relationships between people and the cosmic order that they necessarily produce. If this occurs, then the cultivation and expression of virtue is understood in a way that is self-interestedly anti-social. Manifesting itself in snobbery or crudeness, the self-cultivator's expressions of refinement become as destructive as the subject's pursuit of personal gain at the expense of the state in the HFZ. (Ivanhoe 2000, 5) Yet, the Legalist notion of law distinguishes itself from the rites in the Analects through its consequences for not properly channeling one's bravery. Rewards and punishments both penalize individuals for failing to properly direct their efforts because one of the state's ultimate objectives is contributing to public welfare and state development. In the Analects, there is no institutional penalty and the rites do not trim and shape native tendencies for state-specific objectives.

Under these conditions, the subject of the perpetually evaluating Legalist state must seek to achieve three objectives of his own in order to survive and prosper within the collective. He must first ensure that he engages in behavior that increases the likelihood of obtaining rewards or institutional praise and decreases the likelihood of suffering punishment. A subject must learn where the opportunities for profit and fame are and maximize his personal investment in those areas, while not violating the law or defying state expectations. The ideal countrymen's second objective is to maximize the display of his positive evaluations and conceal negative ones. This doesn't necessarily mean flaunting one's wealth or status. It does mean that one must materially distinguish himself from others as much as he can. A strategy of this kind 
maximizes the amount of positive social reinforcement a subject will receive from his peers.

Lastly, the subject must prioritize the state as his primary audience. A subject must understand that it is far more important to pursue his personal gain in accordance with state law than it is to do so according to familial expectation. Indicating how the Legalist state laws largely determine the degree to which all subjects obtain personal gain, the $H F Z$ describes the state as possessing the wealth, strength, and authority to impact a subject more than any parent. (Chen 2000, 18.46.1009) We can thus surmise that an ideal member of a Legalist collective understands that there are times when family or social values may be out of step with state objectives. When this occurs, the ideal countryman should not prioritize the satisfaction of familial expectation over compliance with state law. The consequences of failing to comply with state command are far more severe than any punishment from a parent.

How can this be the case? Consider the Legalist creation of mutual responsibility groups. Rewards and punishments can be bestowed in such a way that one's family or friends suffer similar deprivation or punishment upon a subject's failure to comply with state expectations. Placing state values at the foundation of family ethics, “Charting the Policies" (Hua-Ce 畫策) describes how violation of the law or neglect of orders would result in not just the soldier's but his father's, brothers', and wife's death as well. (Gao 2011, 147) We first should recall that the aforementioned "Inner Compendium of Explanations, Upper" passage communicated a similar promotion of the martial spirit. The King sought to inculcate a bellicose energy and spirit within his subjects so that he could ensure success in his attack on an enemy state. This "Charting the Policies" passage further illustrates how the Legalist hidden curriculum engages in "military indoctrination". (Pines 2017, 94) It dehumanizes the ruler's subjects, comparing them with hungry wolves, but dehumanized soldiers of enemy states even moreso, comparing the act of killing them to the satisfaction of hunger. In both "Charting the Policies" and "Inner Compendium of Explanations, Upper", the state seeks to inculcate more bravery and bellicosity into countrymen because these characteristics were considered vital for cultivating a more wartime-ready populace.

Most importantly, state policy advocated in "Charting the Policies" is clearly formulated to connect the lives of family members to an individual's failure on the battlefield. In the case of desertion or defeat, a soldier's father, older brother, and wife could be killed. As a result, the law, infused with the prioritization of warfare, inserts itself at the foundation of familial relations. ${ }^{12}$ In short, compliance with the law and productivity within state-promoted channels become requirements to fulfill familial obligations. The author even appears to assume existing cultural and ethical values

\footnotetext{
${ }^{12}$ Luo, Xie, and Luo explain that this form of collective punishment is an important method of promoting the Legalist notion of good faith and mutual trust (xin 信). Not only do family members of soldiers essentially act as collateral, but the system of ranks ties the fate of soldiers in a unit together. Luo, Xie, and Luo add that this has at least three benefits: 1) both sides benefit (the ruler and state win battles, the soldiers get rewards); 2) soldiers build a trustworthiness credit; 3 ) the creation of a system of supervision. (Luo, Xie, Luo 2015, 25)
} 
that place importance on protecting and providing for one's family members. How else would such a policy be efficacious? Thus, the moral compass of all individual subjects begins with their duties to interests beyond the self and the family, making secondary one's private ( $s i$ 私) obligations to himself, his family, and his acquaintances.

\section{POWER}

Although many aspects of power can be seen in the discussions of both "crowds" and "praise", I will nevertheless provide a more comprehensive sketch here. With regards to "power", Jackson asserts that students must become accustomed to a phenomenon of "unequal power" related to the "evaluative aspects of classroom life" but it "involves much more than the distribution of praise and reproof". (Jackson 1983, 52) Just as a classroom concentrates the influence over its day-to-day activities in the hands of a teacher, political visions in the $B L S$ and $H F Z$ concentrate the ultimate authority over state activities in the hands of the ruler. At least three aspects of the sovereign's power are independent from but nevertheless closely linked to the aforementioned "crowds" and "praise" aspects of the Legalist state's hidden curriculum.

First and foremost, the ruler decides which values will inform how state mechanisms are implemented, what state practices the mechanisms will enforce, and what constitutes state development. If all countrymen have duties to contribute to state order and development and these obligations require the acquisition of some attitudes, sensibilities, and qualities, then the ruler's emphasis on agriculture and warfare effectively influences, inadvertently or not, aspects of his subjects' personalities through how he defines state development and social practice. The chapter "Having Standards" (You-Du 有度) [1] provides useful evidence in this regard when it describes how the ruler should even effectively control his subjects' physical features, preventing them from speaking and seeing for their own private interests. (Chen 2000, 2.6.99) Although this passage specifically has the ruler's ministers in mind, its fundamental point can be applied to all subjects of a Legalist state: the ruler should oppose everything, even the use of mouths and eyes, that involves subject pursuit of personal gain at the expense of the state.

This interpretation is confirmed when the same chapter later provides insight about its definitions for uprightness, loyalty, benevolence, and righteousness. Addressing these qualities in the negative form, describing what they are not, "Having Standards" [2] dismisses these qualities because they are not shaped by the state values that are inseparable from the ruler himself. (Chen 2000, 2.6.99-100) If rank and emoluments are only obtained through farming or military merit, then to make light of rewards is to behaviorally demonstrate a lack of concern for contributing to state development as one pursues personal gain. So the $H F Z$ insists that subjects cannot truly be upright without also productively engaging in activities the state deems important. 
The same applies, and perhaps even more so, to righteousness and loyalty. The lifestyles of recluses and persuaders represent an individual choice to abstain from the toil of agricultural production and the danger involved in achieving military merit. Devoting one's labor and energy to pursuing activities that do not contribute to state development neglects the duties a subject has to his institutionalized collective. According to the $H F Z$, the lack of productivity of recluses and those that reproach the ruler ignores the operational requirements for the state to survive and prosper. Conforming to both state objectives and expectations, righteousness in "Having Standards" [2] refers to the subject's fulfillment of his state duties to the ruler and fellow countrymen through productivity within ruler-approved channels.

What the world defines as loyalty encounters a similar problem in the ideal state in "Having Standards". Turning one's back on his ruler disqualifies him from being loyal. The ruler creates the laws and infuses them with values suitable for the times and circumstances. To defy the ruler is to defy the very foundation of the law. Violation of the law is a shirking of one's responsibility to the state. This only demonstrates loyalty to self-preservation rather than a commitment to contribute to the welfare of one's collective.

Another important aspect of the ruler's power is his monopolistic control over the distribution of resources within the state. Law is typically rationalized in the $B L S$ and the $H F Z$ as a tool of governance most capable of accommodating human nature. However, as our discussion of "crowds" revealed, the ruler's administration of the law is informed by a vision for political and social organization that conflicts with the externalities of natural human proclivities. On the one hand, the $H F Z$ views human nature as inherently self-interested or anti-social. People primarily make decisions and behave according to their own personal preferences and tastes. On the other hand, law is a mechanism that coerces the pursuit of self-interest to manifest itself in statecooperative and state-contributive ways. This requires that subjects restrain themselves in ways they otherwise would not. "Outer Compendium of Explanations, Lower Right" illustrates this when King Zhaoxiang, even during a famine, asserts that he would rather maintain the integrity of his culture of merit and allow many of his subjects to die than provide disaster relief to those who lacked merit. (Chen 2000, 14.35.818-819)

The King's mentality reveals an important assumption: when merit is not a condition for obtaining personal gain, chaos is necessarily the result. Why? Rewards are bestowed on individuals who have accumulated merit; while merit can only be earned through high performance in agriculture and warfare. If the ruler distributes vegetables from the Five Gardens without the prerequisite of merit, then this communicates to his merit-possessing and merit-lacking subjects that personal gain is not contingent upon the achievement of merit. Once subjects become aware of this, then the above passage suggests that most, if not all, of them will choose not to devote themselves to ruler-approved channels. In other words, subjects define selfinterest with little regard for the interest of the state collective. As a result, the King 
must take this into account and stave off the conflict that directly results from the self-interestedly anti-social quality of human nature in its rawest form. ${ }^{13}$

Beyond our disaster relief scenario, the $H F Z$ also conveys one of its most important rationalizations for state law: enabling the state to avoid destructive competition. When the state has no law or system of merit to regulate the distribution of wealth and resources, the default ways that human beings interact with each other is through violent struggle. ${ }^{14}$ This may not pose a problem for some individuals or even small families and clans, but communities of much larger populations, like states, require far more cooperation for their survival and prosperity. Hence, without creating and maintaining an architecture of governance that adequately benefits most within a large human community, the state has no way of defending itself against violent intra-state competition for resources and power. In fact, the same term, 'zheng', describing a violent conflict between members of the same community in "Outer Compendium of Explanations, Lower Right", is used to describe a destructive form of competition in the $B L S$ as well. "Methods of War" (Zhan-Fa 戰法) defines true kingship as having political victory in which "the people do not fight one another" and "there is timidity in battles within towns". (Gao 2011, 102) Thus, the ruler's monopolistic control over the distribution of resources is rationalized in an egalitarian fashion. Such a condition is necessary to save the state collective from harming itself.

A corollary to the ruler's formulation of values and control over resources, the granting of privilege, is a third aspect of sovereign power that is produced by a state's culture of merit. Not only did the King have a very clear conception of which subjects were deserving of resources (merit-possessing) and which ones were not (meritlacking), but the magnitude of maintaining such a distinction was shown in at least two different ways. The first is that the King considered disorder to be the inevitable result of failing to distinguish merit-possessing and merit-lacking countrymen. This argument is consistent with the evolution of human organization found in both the $B L S$ and the HFZ. The ruler, his laws, and state officials were all necessary to prevent the inevitable chaos that would result without them. The King in our "Outer Compendium of Explanations, Lower Right" story not only reflects the same idea, but he extends it further. He adds that a culture of merit that communicates why some subjects are more deserving of privilege than others is necessary to legitimize the

\footnotetext{
${ }^{13}$ The issue of the democratic or impersonal quality of the ruler's governance undoubtedly remains a subject of debate. For instance, Goldin (2005) suggests that the HFZ merely represents an amoral doctrine of self-interest, in which 'gong' (公) is nothing but the ruler's self-interest. While Goldin allows for the idea that 'gong' can include residual benefits for the subjects, his suggestion still obscures the critical impersonal aspect of the ruler's self-interest that partially legitimizes the ruler's authority in the HFZ. Understanding the HFZ's ideal state as a battleground of interests is also articulated in earlier studies such as Graham (1989) and Jin (1980). In fact, Jin asserts the foundation of HFZ's political vision rests on the conflicting interests of the ruler, his ministers, and the common people and how the ruler should not place his trust in any person and should take precautions against everyone. (Jin 1980, 41)

${ }^{14}$ This idea of course represents a precedent for Hobbes' assertion about the life of man in the state of nature, describing it as "solitary, poore, nasty, brutish, and short". (Hobbes 1968, 186)
} 
ruler's vision for social and political organization in the minds of all members of the collective.

The significance of the distinction between the deserving and undeserving is also seen in the King's attitude towards death. When presented with a choice between enabling subjects to live and not maintaining a distinction between the deserving and undeserving or allowing subjects to die and maintaining a distinction between meritpossessing and merit-lacking subjects, the King was clear: the latter is the most desirable option. If the reader can look past the inadequate regard for human life, she will at least notice how the King viewed teaching subjects the terms by which they would be deserving of privilege as indispensable to their very existence within his state. I am reminded of Meng Zi 6A10.1-10.2. ${ }^{15}$ Meng Zi proclaims that despite his desire for life, he would never forsake righteousness for its sake.

Like righteousness in the Meng-Zi, subjects learn the connection between state values and privilege is so paramount that their existence without it is worse than no life at all. To put it another way, the state is analogous to Meng Zi himself. Although it may value the lives of individual subjects, it too desires to achieve its pedagogical objectives. If the King is forced to choose between the lives of individual subjects and upholding a distinction between the deserving and undeserving, he will choose to uphold the learning outcome. Although there may be individual lives lost as a result of such a decision, the King is far more concerned about the death of the state and society. Thus, we can infer that the state's pedagogical objectives are fundamentally more vital to state life than the lives of individual subjects.

Our Legalist texts of focus also indicate an understanding of the distinct qualities of the ruler's power relative to other forms of authority. The aforementioned "Charting the Policies" passage demonstrated an awareness of the fact that a member of a Legalist collective does not first encounter authority when subjected to state law. Before one comes of age and performs state duties on his own, he first learns to comply with the wishes of parental authority. However, the HFZ explains how the qualities of the two authority figures are very different. For instance, state authority is impersonal and narrow relative to parental authority. (Chen 2000, 18.46.1006)

We have already seen how impersonally the state must govern its subjects. Unlike the ruler, parents can tailor their approach to their child's particular personality and gender. We have also seen how rewards and their culture of merit create a very narrow method of determining subject worth. Unlike the ruler, parents can recognize aspects of their children's personalities that are well beyond the purview of state development. These aspects necessarily distinguish the pedagogical aspects of the relationships between ruler-subject and parent-child.

Nevertheless, the $H F Z$ also mentions an important similarity in order to legitimize the impersonality of the ruler-subject relationship. It asserts that the parent-child relationship cannot be completely characterized by mutual affection because it also has an impersonal aspect to it. Parents treat their children differently based on how

\footnotetext{
${ }^{15}$ A translation can be found in Mengzi 《孟子》; trans. Bryan W. Van Norden (2008), Mengzi: With Selections From Traditional Commentaries (Indianapolis: Hackett Publishing Company, Inc.).
} 
much they will be able to produce economically in the future. Due to this phenomenon, the $H F Z$ effectively argues that the state's narrow concern for subject contribution to state wealth should be conceptualized as merely a reproduction of the impersonal aspects that exist in parent-child relationships. In other words, the $H F Z$ posits that if parents evaluate their children based on their potential for economic production for the family, why would a ruler not evaluate his subjects based on their contribution for state development?

A quality that distinguishes the ruler's authority from parental authority is the capacity for force. "The Five Vermin" [3] suggests that the greater an authority's capacity for force, the more effective it will be pedagogically. (Chen 2000, 19.49.1099) Essentially comparing authority figures and their respective methods of teaching children, the chapter emphasizes the relative weakness of non-state-based authority. Parents, villagers, teachers, and elders were associated with methods of teaching through love, social reinforcement, and imparting wisdom respectively. The text addresses parental love most directly, specifically calling it insufficient ( $b u-z u$ 不 足). Ultimately illustrating the supremacy of the ruler's authority, “The Five Vermin" [3] declares that the harsh punishments in the control of the sovereign are sufficient to produce new behavior within a boy who did not respond to all other authority figures.

What differentiates the state from parents, villagers, teachers, and elders is the magnitude of fear it can instill. Its ability to impose the most painful, damaging, and impoverishing conditions all people seek to avoid dwarfs any sense of loss experienced from a lack of love, social marginalization, or blocked access to wisdom. Only the ruler's exclusive control of state force causes a child to embrace values beyond his own personal gain. Other sources of authority cannot even coerce a child to fundamentally recalculate his self-interest.

The combination of all of the aforementioned aspects of the ruler's authority collectively create a phenomenon similar to what Jackson called "substitution" (Jackson 1983, 53), in which the ruler's plans for action are prioritized within the subject's own. The earlier "The Five Vermin" [2] passage described agriculture as toil and warfare as dangerous. Based on the assumptions both the $B L S$ and the $H F Z$ make about human behavior, subjects only engage in these activities because of the allure of profit and fame. To put it another way, all countrymen would choose more leisurely and safer pursuits of personal gain if possible. Therefore, as subjects pursue rewards, they come to understand an important lesson that is a direct result of the ruler's power. They learn how to employ their strength in the service of their ruler's desires as they seek their own personal gain. In other words, their ruler's vision for the state and the political action necessary to achieve it is incorporated into and prioritized within each member of the populace's own quest for self-interest and the behavior necessary to achieve it. This explains why we see the $B L S$ 's "Agriculture and Warfare", "Calculating the Land" (Suan-Di 算地), and "Explaining the People" (Shuo-Min 說民) respectively assert: 
...because every morning and night the people are engaged in agriculture, they will love the ruler and sacrifice themselves in compliance with his commands. (Gao 2011, 51)

Those who administer the state are able to completely extract profit from the Earth and cause people to sacrifice themselves [for the sake of the court]. (Gao 2011, 76)

When punishments are awe-inspiring, the people, in fear of receiving them, will sacrifice themselves for their ruler. (Gao 2011, 68)

Now the reader may recall the aforementioned "Opening the Blocked" passage. Describing how people behaved before the creation of the state, it told us how human organization devolved into disorder because people selfishly seized each other's property and destructively competed with one another for the sake of pursuing their own personal gain. So how can the idea that human beings naturally pursue their selfinterests be reconciled with our above examples that hope subjects will sacrifice themselves for the sake of their ruler and state? The answer is clear: a subject's conception of his self-interest undergoes a radical transformation. This is not to say that the state eliminates its subjects' sense of self-interest or each member of the populace overcomes his "intrinsic egoism". (Pines 2017, 92) This is to say that a subject learns to place his ruler's concern for state development at the very foundation of his own pursuit of personal gain. In short, human nature does not change, but how it manifests itself in people's behavior does.

This is a similar pedagogical process to our aforementioned "Charting the Policies" passage, where military policy tied the fates of family members to a soldier's success and failure on the battlefield. Such a policy is designed to fundamentally change a subject's sense of ethics, making the fulfillment of one's state duties as a necessary condition to fulfill one's familial obligations. In terms of self-interest, one's performance in ruler-approved channels directly determines one's material welfare and social privilege. The rewards, punishments, and culture of merit fundamentally change a subject's sense of self-interest and self-worth. This kind of architecture of governance makes the fulfillment of one's state duties a necessary condition for obtaining the wealth and/or nobility along with avoiding impoverishment and social marginalization that largely influence self-worth.

\section{CONCLUSION}

I sought to present my own interpretation of the ideas found in the $B L S$ and the $H F Z$, along with an exploration of their implications, rather than revealing authorial or editorial intent. ${ }^{16}$ Although the $B L S$ and the $H F Z$ may not have envisioned their

\footnotetext{
${ }^{16}$ Yet, we should acknowledge that the focus on ideas can have serious limitations as well because these Legalist texts may have been part of a larger oral tradition. Additionally, the process of writing, production, possible language and structural corruptions, and the potential for archeological finds can all seriously impact how ideas presented in these texts should be interpreted.
} 
governance as pedagogy, contemporary thought on U.S. schooling reveals how subject participation in Legalist state practice educates the populace on five important ideas to guide their positive action: 1) behaviorally expressing oneself as "one of many" within a larger collective that transcends his network of family and acquaintances; 2) learning to defer gratification, regularly being able to delay or deny instinctive behavioral responses to one's impulses and desires; 3) embracing a notion of constructive competition and refraining from destructive forms; 4) prioritizing the ruler's and his state's value system within one's own personal values and ethics; 5) prioritizing the state's development and welfare within one's own definition of selfinterest.

Jackson's notion of the "hidden curriculum" unlocks the less obvious pedagogical quality of Legalist governance. Approaching the $B L S$ and $H F Z$ from a sociological perspective, exhuming ignored structure (cognitive and objective) from the political vision's social world and highlighting their relationship with the state mechanisms that (re)produce them, contributes to our understanding of a question that remains a subject of debate in Chinese philosophy: what characterizes the public space in the ideal Legalist state? Insisting on an inescapable connection between culture and the structure within which it is created, I approached the structural context of the Legalist state as a foundation from which we can surmise facts about subject identity. More specifically, this study focused on how the governance of the institutionalized state structured the individual subject's sense of self. Hence, when rewards and punishments are characterized as tools for manipulating subjects in an effort to merely "explicate personal gains and losses for compliance and transgression" (Pines $2017,95)$, we fail to comprehensively understand the pedagogical depth of the $B L S$ and the $H F Z$.

The hidden curriculum outlined in both texts reveals how the learning process of subjecthood requires more than understanding the sources from which profit and fame spring. This study demonstrates how the behaviors, along with their associated

attitudes and sensibilities, required to obtain wealth and nobility while also avoiding punishment, are supposed to train a subject, through various social situations, to behaviorally express himself within parameters that ensure state collective welfare. This is a basis on which we can begin discussion about common ground or a "synthesis" (Van Norden 2013, 135) between the Legalist and Confucian traditions of thought. When this occurs, the "commitment to the ruler and the state" becomes far more than an "abstract" idea. (Pines 2017, 75) Contribution to one's state collective, satisfying the ruler, and pursuing personal gain all become crucial components of subject identity.

\section{ACKNOWLEDGEMENTS}

I am grateful for critical comments on an earlier draft of this paper from Professor John Lagerwey. Additionally, I benefitted greatly from feedback received from audience members at the 2018 joint Midwest and Northeast Conference on Chinese 
Thought along with the reviewers at Comparative Philosophy. All of the aforementioned helped sharpen this project, from the title and methodology to the analysis.

\section{REFERENCES}

Chen, Qiyou 陳奇猷 (2000), Han-Fei-Zi-Xin-Jiao-Zhu 《韓非子新校注》 $[A \mathrm{New}$ Collation and Annotation of the Han-Fei-Zi] (Shanghai 上海: Shang-Hai-Gu-JiChu-Ban-She 上海古籍出版社).

Ding, Li Li 丁利利 (2016), “Lüe-Lun-Xian-Qin-Fa-Jia-Xiao-Fei-Si-Xiang-Yi-GuanZi-Shang-Jun-Shu-Han-Fei-Zi-Wei-Zhong-Xin”<略論先秦法家消費思想一以 《管子》, 《商君書》, 《韓非子》為中心> [“A Brief Discussion on the PreQin Legalist Thought on Consumption-Focusing on the Guan-Zi, Shang-JunShu, and Han-Fei-Zi”'], Chang-Zhi Xue-Yuan-Xue-Bao 長治學院學報 33 (2016): 34-37.

Gao, Heng 高亨 (2011), Shang-Jun-Shu-Zhu-Yi 《商君書注譯》[Annotation and Translation of the Shang-Jun-Shu] (Beijing 北京: Qing-Hua-Da-Xue-Chu-BanShe 清華大學出版社).

Giroux, Henry A. (2000), "Public Pedagogy as cultural politics: Stuart Hall and the 'crisis' of Culture", Cultural Studies 14.2: 341-360.

Goldin, Paul R. (2005), "Han Fei's Doctrine of Self-Interest”, in Paul R. Goldin, After Confucius: Studies in Early Chinese Philosophy. (Honolulu: University of Hawaii Press,), 58-65.

- (2011), "Persistent Misconceptions about Chinese 'Legalism", Journal of Chinese Philosophy 38.1: 88-104.)

Graham, Angus C. (1989), Disputers of the Tao: Philosophical Argument in Ancient China (La Salle: Open Court).

Guanzi 《管子》; D.C. Lau and Chen Fong Ching (ed.) (2001), A Concordance to the Guanzi (Hong Kong: The Commercial Press).

Handelman, Don (1995), "Cultural Taxonomy and Bureaucracy in Ancient China: The Book of Lord Shang", International Journal of Politics, Culture, and Society 9.2: 263-294.

Hobbes, Thomas (1652; Penguin Edition 1968), Leviathan, C.B. Macpherson (ed.) (London: Penguin Classics).

Huang, Ying-Syuan and Asghar, Anila (2018), "Science education reform in Confucian learning cultures: teachers' perspectives on policy and practice in Taiwan”, Cultural Studies of Science Education 13.1: 101-131.

Ivanhoe, Philip J. (2000), Confucian Moral Self-Cultivation (Indianapolis, IN: Hackett Publishing). 
Jackson, Philip (1983), "The Daily Grind", in Henry Giroux and David Purpel (ed.), The Hidden Curriculum and Moral Education: Deception or Discovery? (Berkeley, CA: McCutchan Publishing Corporation, 1983), 28-60.

Jin, Jing Fang 金景芳 (1980), “Zhan-Guo-Si-Jia-Wu-Zi-Si-Xiang-Lun-Lüe-Ru-JiaMeng-Zi-Xun-Zi-Mo-Jia-Mo-Zi-Dao-Jia-Zhuang-Zi-Fa-Jia-Han-Fei-Zi” <戰國四 家五子思想論略-儒家孟子, 荀子, 墨家墨子, 道家莊子, 法家韓非子> ["Outlining the Thought of the Warring States Four Traditions and Five Thinkers-Confucianism's Meng-Zi and Xun-Zi, Mohism's Mo-Zi, Daoism's Zhuang-Zi, and Legalism's Han-Fei-Zi'], Ji-Lin-Da-Xue-She-Hui-Ke-Xue-XueBao 吉林大學社會科學學報 1 (1980): 21-42.

King, Brandon (2015), "Adapting with the Times: Fajia Law and State Development", Dissertation, Chinese University of Hong Kong.

Levi, Jean (2011), "The Rite, The Norm and The Dao: Philosophy of Sacrifice and Transcendence of Power in Ancient China", trans. John Lagerwey", in John Lagerwey and Marc Kalinowski (eds.), Early Chinese Religion, Part One: Shang through Han (1250 B.C.- 220 A.D.) (Leiden: Brill, 2011).

Lun Yü 《論語》; D.C. Lau (trans.) (1992), Confucius: The Analects (Hong Kong: The Chinese University of Hong Kong).

Lun Yü 《論語》; Edward Slingerland (trans.) (2003), Confucius-Analects: With Selections from Traditional Commentaries (Indianapolis, IN: Hackett Publishing).

Luo, Wei 羅瑋, Xie Yi 謝熠, and Luo Jiao Jiang 羅教講 (2015), “Lun-Fa-Jia-XuePai-Zhong-De-Xin-Ren-Guan-Cong-Guan-Zi-Shang-Jun-Shu-Han-Fei-Zi” <論法 家學派中的信任觀一從《管子》, 《商君書》, 《韓非子》> [“Discussing the Legalist Tradition's Conception of Trust-From the Guan-Zi, Shang-Jun-Shu, and Han-Fei-Zi”'], Guan-Zi-Xue-Kan 管子學刊 1 (2015): 22-26.

Mengzi 《孟子》; Bryan W. Van Norden (trans.) (2008), Mengzi: With Selections From Traditional Commentaries (Indianapolis: Hackett Publishing Company, Inc.).

Mills, C. Wright (2008), The Politics of Truth: Selected writings of C. Wright Mills (New York: Oxford University Press).

Mozi 《墨子》; Ian Johnston (trans.) (2010), The Mozi: A Complete Translation (New York: Columbia University Press).

Olberding, Amy (2012), Moral Exemplars in the Analects: The Good Person is That (New York: Routledge).

Pines, Yuri (2017), The Book of Lord Shang: Apologetics of State Power in Early China (New York: Columbia University Press).

Sandlin, Jennifer A., Schultz, Brian D., and Burdick, Jake (eds.) (2010), Handbook of Public Pedagogy. (New York: Routledge).

Schneider, Henrique (2014), "Han Fei and Justice", Cambridge Journal of China Studies 9.4: 20-37.

Song, Hong Bing 宋洪兵 (2007), "Han-Fei-Zi-Zheng-Zhi-Si-Xiang-Zai-Yan-JiuGang-Yao-Gong-Shi-Shi-Yu-Zhong-Zheng-Zhi-Jia-Zhi-Yu-Zheng-Zhi-Cuo-Shi- 
De-You-Ji-Rong-He” <韩非子政治思想再研究綱要一共識視域中政治價值與 政治措施的有機融合> [“A Re-examination of the Han-Fei-Zi's Political Thought: Common Ground about Political Worth and its Organic Synthesis of Political Measures], Dong-Bei-Shi-Da-Xue-Bao-Zhe-Xue-Shi 東北師大學報 2 (2007): 38-43.

Van Norden, Bryan W. (2013), "Han Fei and Confucianism: Toward a Synthesis", in Paul R. Goldin (ed.), Dao Companion to the Philosophy of Han Fei (New York: Springer), 135-145.

$\mathrm{Xu}$, Jianliang 許建良 (2012), Xian-Qin-Fa-Jia-De-Dao-De-Shi-Jie 《先秦法家的道 德世界》[The Moral World of the Pre-Qin Legalists] (Beijing 北京: Ren-Min Chu-Ban-She 人民出版社).

Yuan, Jin 袁勁 (2017), “Xian-Qin-Fa-jia-Lun-'Yuan'-Yi-Guan-Zi-Shang-Jun-ShuHan-Fei-Zi-Wei-Zhong-Xin” <先秦法家論 “怨” 以《管子》，《商君書》， 《韓非子》為中心 $>$ ['Pre-Qin Legalist discussions on 'Resentment'-Focusing on the Guan-Zi, Shang-Jun-Shu, and the Han-Fei-Zi”], Guan-Zi-Xue-Kan 管子學 刊 2 (2017): 24-30.

Zhao, Dingxin (2015), The Confucian-Legalist State: A New Theory of Chinese History (New York: Oxford University Press). 